\title{
Using Simulation Speeds to Differentiate Controller Interface Concepts
}

\author{
Anna Trujillo and Alan Pope \\ NASA Langley Research Center \\ Hampton, VA
}

\begin{abstract}
This study investigated two concepts: (1) whether speeding a human-in-the-loop simulation (or the subject's "world") scales time stress in such a way as to cause primary task performance to reveal workload differences between experimental conditions and (2) whether using natural hand motions to control the attitude of an aircraft makes controlling the aircraft easier and more intuitive. This was accomplished by having pilots and non-pilots make altitude and heading changes using three different control inceptors at three simulation speeds. Results indicate that simulation speed does affect workload and controllability. The bank and pitch angle error was affected by simulation speed but not by a simulation speed by controller type interaction; this may have been due to the relatively easy flying task. Results also indicate that pilots could control the bank and pitch angle of an aircraft about equally as well with the glove as with the sidestick. Non-pilots approached the pilots' ability to control the bank and pitch angle of an aircraft using the positional glove - where the hand angle is directly proportional to the commanded aircraft angle. Therefore, (1) changing the simulation speed lends itself to objectively indexing a subject's workload and may also aid in differentiating among interface concepts based upon performance if the task being studied is sufficiently challenging and (2) using natural body movements to mimic the movement of an airplane for attitude control is feasible.
\end{abstract}

\section{INTRODUCTION}

This study investigated two concepts: (1) whether speeding a human-in-the-loop simulation (or the subject's "world") scales time stress in such a way as to cause primary task performance to reveal workload differences between experimental conditions and (2) whether using natural hand motions to control the attitude of an aircraft makes controlling the aircraft easier and more intuitive.

Speeding up and slowing down the world (or simulation) may affect workload. If workload is low, the world can accelerate to some speed beyond real time without a decrement in performance. If workload is high, as the world slows down, performance improves up to a point. Therefore, the change in speed from real time to the point at which performance changes (either degrades or ceases to improve) would indicate the workload level.

As Pope and Bowles (1982) wrote: ... [T] he time scale of the simulation can be skewed so that the entire "world" surrounding the pilot is either slowed or speeded relative to real time (and pilot reaction time). As the environment departs from real time in the slowing direction, an operator experiences the same set of tasks as less demanding. Conversely, as the virtual world of the simulator is quickened beyond real time, the operator experiences the same set of tasks as more demanding.

Using natural hand motions to control aircraft attitude would allow for more intuitive control of the aircraft and might allow the operators to do control movements in a more concurrent manner rather than in a sequential manner. An example of this would be turning, descending, and slowing the aircraft with one combined hand movement rather than the three separate movements that are required using traditional cockpit controls. With more intuitive controls, Fitzmaurice, et al. (1995) found that people naturally did these functions in parallel. In fact, they felt that more traditional interfaces hindered operators since they could not move in natural ways
(Fitzmaurice et al., 1995). But with use comes comfort; nonpilots will prefer hand motions while pilots (with a higher level of experience) will prefer the stick and rudder method (Bartlett, 2000). This concepts also implements the Wings idea described by Schutte (1997), which has the operator "remain aware of the aircraft through natural interpretation."

Related research in controlling aircraft with the body has been done at NASA Ames where scientists used muscle nerve signals to control an aircraft (Bluck, 2001). When muscle nerve signals are used, though, direct feedback and rapid response is needed in order to avoid pilot induced oscillations (PIO) (Hogan, 1976). Another concern is that continual human control like this may fatigue the operator (Milgram, Zhai, \& Drascic, 1993), which may in turn induce PIO if microtremors are not filtered out.

These observations suggested an experimental methodology for comparing interface design concepts based upon conducting a series of simulator runs with each concept at several simulation time scale points corresponding to multiples of real time.

The interface concepts used a glove so that the hand changed aircraft bank angle and pitch angle. Using the hand to control these inputs was chosen for several reasons. First, pilots (and non-pilots) often describe flying through the air using their hand. Second, learning to pilot aircraft using a joystick or other grasped controller and throttle controls, requires acquisition of particular motor-skill coordinations that are not intuitive. It is expected that a more intuitive method of commanding aircraft flight would reduce the amount of flight training time and errors (Schutte, 1997). Third, in high stress situations, human controllers tend to revert to more primitive, intuitive modes of functioning and abandon acquired skills. Lastly, manual flight control typically requires mental integration of flight control parameters, such as banking requiring a pitch up to maintain altitude. With intuitive hand control, flight control functions are intrinsically integrated and not artificially separated, reducing the workload demands of function coordination. 
Furthermore, performance with a better design concept would not be expected to degrade as rapidly as performance with an inferior concept as simulation speed is increased. This difference in the way task performance responds to changes in task time demand or time stress provides a means of discriminating the workload imposed by tasks when the adaptability of the subject obscures the difference in real time.

\section{Objective}

The objectives of this study were to determine (1) whether increasing the speed of the "world" scales time stress in such a way as to cause primary task performance to reveal workload differences between experimental conditions and (2) whether an operator could control the pitch and bank angle of a simulated business jet using hand motions.

\section{METHOD}

\section{Subjects}

The 12 subjects were NASA Langley employees and contractors. Half of the subjects were current certificated pilots with at least a Class III medical certificate (Federal Aviation Administration, 2006). The rest of the subjects were non-pilots. The average age of the pilots was 50 years and the average age of the non-pilots was 30 years. The pilots had an average of 26 years experience and an average of $8650 \mathrm{hrs}$ of flight experience.

\section{Independent Variables}

Speed of simulation. Each subject had data runs at 3 simulation speeds: 1 (unity), 1.3, and 2. Unity was defined as being real-time and 2 was defined as twice real time. The whole simulation speed changed, analogous to hitting the fast forward button during play on VCRs. Simulation speed 2 was chosen because there was confidence that performance differences would be seen at that speed although subjects were likely to detect the change in simulation speed. The 1.3 simulation speed was chosen because a non-detectable change in simulation speed by subjects was desired.

Controller type. Each subject controlled the simulated aircraft with hand movements (glove control) during one set of experimental runs and with a sidestick during a second, identical set of runs. For the glove control, hand movements changed the bank and pitch angles of the simulation.

Bank angle was controlled by the roll variable on the glove. A hand roll to the right caused an aircraft bank to the right and a hand roll to the left caused an aircraft bank to the left. Two types of turning methods were employed but each subject saw only one method in order to reduce negative transfer effects of glove control methods. With the first method, the hand roll angle was proportional to the aircraft bank angle (positional) (Equation 1); therefore, the hand must maintain a roll angle in order to have the aircraft maintain the turn. With the second method, the hand roll angle is proportional to the rate of turn of the aircraft (rate) (Equation 2); therefore, the hand must return to neutral (level) once the desired aircraft bank angle is reached otherwise the aircraft bank angle will keep increasing.

$$
\begin{aligned}
& \angle_{\text {hand roll }}=K_{1} * \angle_{\mathrm{a} / \mathrm{c} \mathrm{bank}} \\
& \angle_{\text {hand roll }}=K_{2} * \frac{\partial}{\partial t}\left(\angle_{\mathrm{a} / \mathrm{c} \mathrm{bank}}\right)
\end{aligned}
$$

Pitch angle was controlled by the pitch variable on the glove. A hand pitch down decreased the aircraft pitch angle (pitch down) and a hand pitch up increased the aircraft pitch angle (pitch up). As with the bank angle, two types of control methods were used. With the first method, the hand pitch angle was proportional to the aircraft pitch angle (positional) (similar to Equation 1); therefore, the hand must maintain an angle in order to maintain the aircraft pitch attitude. With the second method, the hand pitch angle was proportional to the rate of pitch for the aircraft (rate) (similar to Equation 2); therefore, the hand must return to level once the desired aircraft pitch attitude is reached otherwise the aircraft pitch attitude will keep increasing.

For sidestick control, sidestick movements changed the bank and pitch angles of the simulation. The control methods for the sidestick controller were analogous to the methods for the glove control, e.g., tilting the sidestick to the right caused an aircraft bank to the right. Furthermore, the sidestick controller used the rate controller method (similar to Equation 2 ), which is typically seen in aircraft.

\section{Dependent Variables}

The primary dependent variables were the aircraft's actual bank and pitch angle compared to the flight director's indicated bank and pitch angle needed to remain on course. These were calculated as root mean square (RMS) errors between the aircraft's actual bank and pitch angle, and the flight director's commanded bank and pitch angle.

The time taken to answer two situation awareness questions was also analyzed. These questions were asked ten seconds before and after each maneuver. The time to answer these questions was the interval between the time the subjects provided an answer and the time when the question was asked.

\section{Procedure}

When subjects first arrived, they signed a consent form before hearing a verbal briefing on the experiment tasks. Subjects then moved to the simulator where they completed two practice runs with the first controller type and its associated control method (controller type was counterbalanced across subjects - half of the subjects used the sidestick first and then the glove where half of those subjects used the positional glove and the rest used the rate glove; half of the subjects used the glove first where half of those subjects used the positional glove and the rest used the rate glove and then the sidestick second). After the practice runs, subjects completed 12 data runs. During each run, subjects had to accomplish one flight level change and one heading change. These maneuvers were shown on the map display and on the primary flight display (PFD) using the flight director. Ten seconds before a maneuver (i.e., heading or altitude change) started ("before"), the 
subject answered either a verbal addition or an orientation (e.g., What is your current altitude?) question. Ten seconds after the maneuver was started ("after"), the subject again answered a verbal addition or an orientation question.

For each run, the simulation speed was either 1, 1.3, or 2; subjects were not notified of this variable. The simulation speed order was counterbalanced across the sidestick and glove (positional and rate) controllers.

At the end of each run, subjects completed the NASATLX workload measure questionnaire (Byers, Bittner, \& Hill, 1989; Hart \& Staveland, 1988) and a Cooper-Harper (CH) controllability scale rating (Cooper \& Harper, 1969; Harper \& Cooper, 1986).

Finally, subjects completed a similar set of runs with the second controller type and its associated control method.

\section{Apparatus}

The simulations ran on two PCs running Windows ${ }^{\mathrm{TM}} \mathrm{XP}$ Professional. They had a redraw refresh rate of $60 \mathrm{~Hz}$ and a graphics update rate of $30 \mathrm{~Hz}$. An out-the-window (OTW) view was on a 30 -inch LCD screen in the upper middle of the layout. The PFD was on the left screen below the OTW display and the map display was on the right screen below the OTW display. The systems display was to the right of the map display. The NASA-TLX and CH questionnaires were to the left of the PFD. These four touch screens were 19-inch LCD screens with an Elo Touchsystems IntelliTouch overlay for touch-screen capability. The sidestick used was a Saitek Cyborg evo joystick (Saitek Ltd., 2003). Subjects used their left hand to maneuver the sidestick. The glove was a 5DT Data Glove 5 (Fifth Dimension Technologies -- 5DT, 2000). Subjects used their right hand when using the glove.

The aircraft simulation was of a Citation X aircraft. The aircraft dynamics were modeled in STAGE v9.2 from Presagis. VAPS v6.4.1, also from Presagis, was used for generating the displays.

\section{Data Analysis}

Data was analyzed using SPSS $®$ for Windows v15. The data was analyzed using a 3-way ANOVA and a linear regression model with simulation speed, controller type, and pilot status (pilot vs. non-pilot) as the independent variables.

The time to answer the verbal questions was the difference in time between when subjects answered the question and when the question was asked. The $\mathrm{CH}$ ratings were on an integer scale. For the NASA-TLX ratings, the six dimensions of workload were normalized to a 100-point scale and then averaged together.

\section{RESULTS}

\section{Bank and Pitch Angle RMS Error}

Simulation speed (bank: $F_{(2,17)}=28.72, \mathrm{p}<0.01$; pitch: $F_{(2,17)}=9.17, \mathrm{p}<0.01$ ), pilot status (bank: $F_{(1,17)}=173.43$, $\mathrm{p}<0.01$; pitch: $F_{(1,17)}=135.24, \mathrm{p}<0.01$ ), controller type (bank:
$F_{(2,17)}=24.72, \mathrm{p}<0.01 ;$ pitch: $\left.F_{(2,17)}=28.82, \mathrm{p}<0.01\right)$, and pilot status by controller type (bank: $F_{(2,17)}=56.73, \mathrm{p}<0.01$; pitch: $\left.F_{(2,17)}=29.15, \mathrm{p}<0.01\right)$ significantly affected both heading and pitch angle RMS errors. In general, the RMS error increased linearly with increasing simulation speed. In fact, linear regressions for bank and pitch angle RMS errors were significant $(\mathrm{p} \leq 0.05)$ (bank angle RMS error $=8.05 *$ simulation speed $\left(\mathrm{R}^{2}=0.73\right)$ and pitch angle $\mathrm{RMS}$ error $=1.81 *$ simulation speed $\left(\mathrm{R}^{2}=0.59\right)$ ) (Figs. 1 and 2$)$. It did not matter much which controller pilots used; but non-pilots performed as well as pilots when using the glove-positional controller (Fig. 3).

Although not significant, the controller type by simulation speed did show some interesting patterns (Table 1). For both the bank and pitch angle RMS error regression on simulation speed, the glove-positional controller had the smallest slope. Therefore, as simulation speed increases, the glove-positional controller performance will degrade the least.

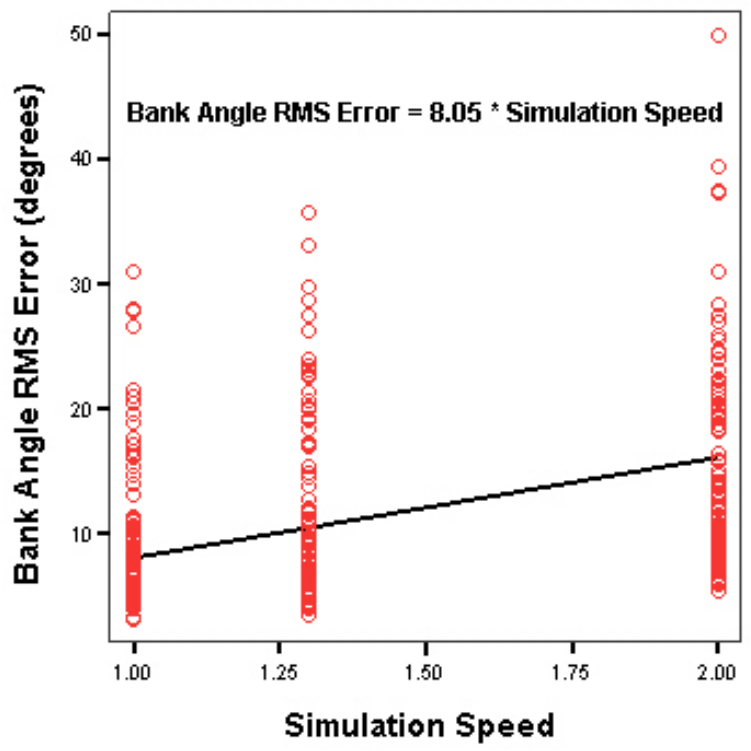

Figure 1. Bank Angle RMS Error by Simulation Speed for Each Trial with the Linear Regression Line

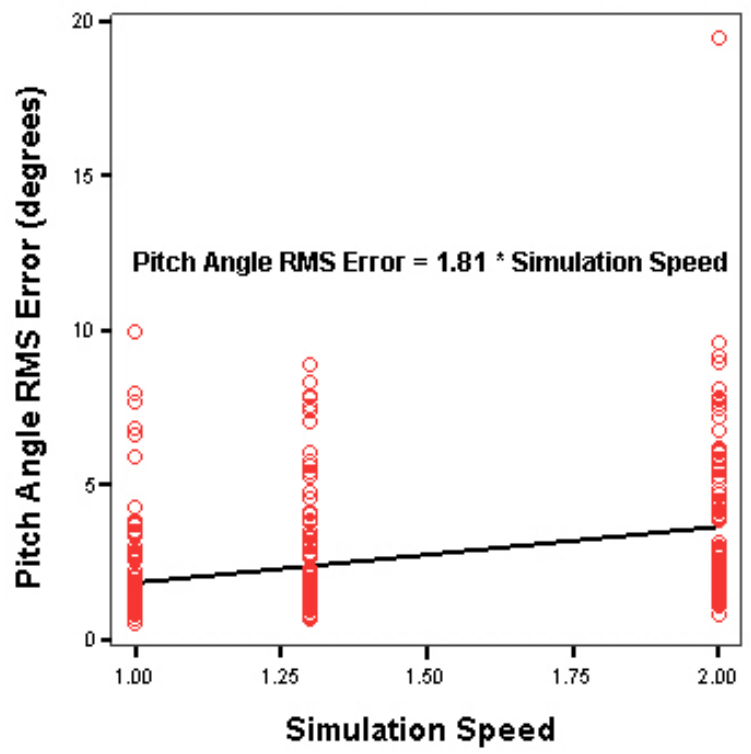

Figure 2. Pitch Angle RMS Error by Simulation Speed for Each Trial with the Linear Regression Line 


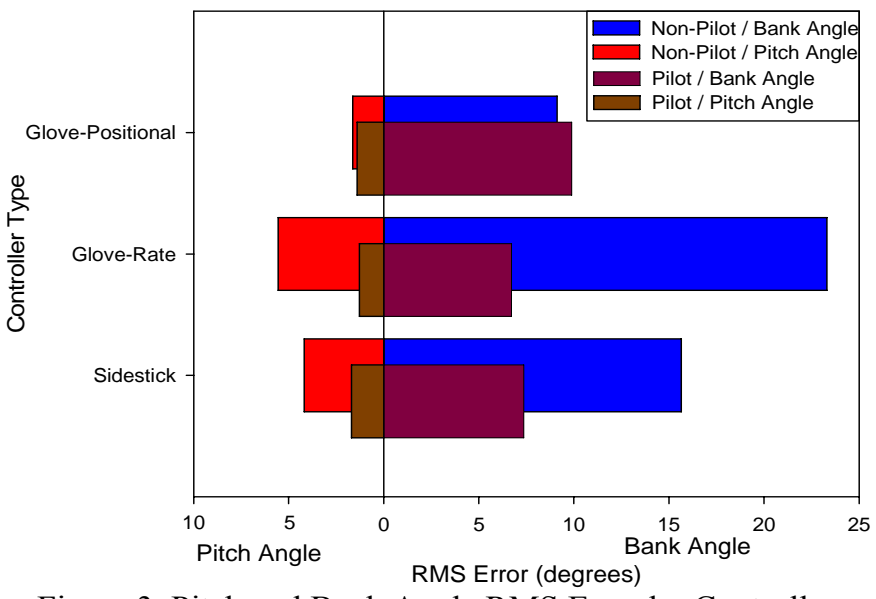

Figure 3. Pitch and Bank Angle RMS Error by Controller

Type and Pilot Status

Table 1. Bank and Pitch Angle RMS Error vs. Simulation Speed Regression Line Slopes by Controller Type

\begin{tabular}{|l|c|c|}
\hline Controller Type & $\begin{array}{c}\text { Bank Angle } \\
\text { RMS Error } \\
\text { Slope }\end{array}$ & $\begin{array}{c}\text { Pitch Angle } \\
\text { RMS Error } \\
\text { Slope }\end{array}$ \\
\hline Sidestick & 7.91 & 2.01 \\
\hline Glove-Rate & 10.10 & 2.30 \\
\hline Glove-Positional & 6.37 & 0.99 \\
\hline
\end{tabular}

\section{CH and NASA-TLX Ratings}

In general, the difficulty of the control task was not high. The mean $\mathrm{CH}$ rating was 3.5 with a standard error of the mean of 0.07 . The mean of the workload rating was 38.6 with a standard error of the mean of 0.80 . Controller type by simulation speed $\left(F_{(4,17)}=3.51, \mathrm{p}<0.01\right)$, controller type $(\mathrm{CH}$ : $F_{(2,17)}=8.44, \mathrm{p}<0.01$; NASA-TLX: $\left.F_{(2,17)}=8.85, \mathrm{p}<0.01\right)$ and pilot status by controller type $\left(\mathrm{CH}: F_{(2,17)}=4.13\right.$, p $<0.02$; NASA-TLX: $\left.F_{(2,17)}=6.64, \mathrm{p}<0.01\right)$ were significant. All controller concepts had equal $\mathrm{CH}$ ratings at the 1.3 simulation speed (Fig. 4). At unity, the sidestick had the lowest $\mathrm{CH}$ rating but at a simulation speed of 2 , the sidestick and glovepositional had equal $\mathrm{CH}$ ratings. Interestingly, pilots rated the glove-rate with the highest $\mathrm{CH}$ rating and workload (Table 2).

\section{Time to Answer Situation Awareness Questions}

Addition problem. The maneuver type (heading or altitude change) did not affect how long it took subjects to answer the addition question but the effect of simulation speed was significant (before: $F_{(2,17)}=49.16, \mathrm{p}<0.01$ and after: $\left.F_{(2,17)}=99.67, \mathrm{p}<0.01\right)$. Furthermore, a linear regression was significant and the equations were the same (add time $=4.52 *$ simulation speed (before: $\mathrm{R}^{2}=0.87$ and after: $\mathrm{R}^{2}=0.94$ )).

Orientation question. As with the addition problem, maneuver type did not affect how long it took subjects to answer the orientation question but the effect of simulation speed was significant (before: $F_{(2,17)}=55.36, \mathrm{p}<0.01$ and after: $\left.F_{(2,17)}=46.05, \mathrm{p}<0.01\right)$. Furthermore, a linear regression was significant and the equations are essentially the same ("before" orientation question time $=5.46 *$ simulation speed

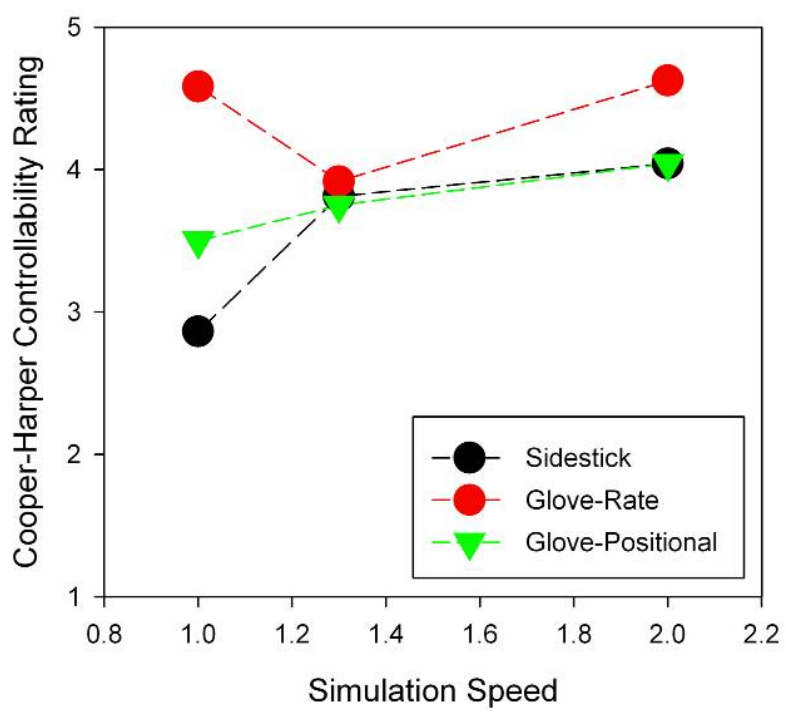

Figure 4. CH Controllability Ratings by Simulation Speed and Controller Type

Table 2. CH Controllability and NASA-TLX Ratings by Controller Type and Pilot Status

\begin{tabular}{|l|c|c|c|c|}
\hline \multirow{2}{*}{$\begin{array}{c}\text { Controller } \\
\text { Type }\end{array}$} & \multicolumn{2}{|c|}{ CH Rating } & \multicolumn{2}{c|}{ NASA-TLX } \\
\cline { 2 - 5 } & Pilot & Non-Pilot & Pilot & Non-Pilot \\
\hline Sidestick & 3.07 & 3.36 & 38.65 & 32.27 \\
\hline Glove-Rate & 4.75 & 4.00 & 50.46 & 37.03 \\
\hline $\begin{array}{l}\text { Glove- } \\
\text { Positional }\end{array}$ & 3.80 & 3.72 & 34.62 & 35.16 \\
\hline
\end{tabular}

CH: 1=best, $10=$ worst

NASA-TLX: $0=$ no workload, 100=high workload

$\left(\mathrm{R}^{2}=0.92\right)$ and "after" orientation question time $=$ $5.19 *$ simulation speed $\left.\left(\mathrm{R}^{2}=0.46\right)\right)$.

\section{Final Questionnaire}

Subjects felt that it was easier to control heading $\left(F_{(2,5)}=28.61, \mathrm{p}<0.01\right)$ and altitude $\left(F_{(2,5)}=17.74, \mathrm{p}<0.01\right)$ with the glove. They also felt using the glove was more intuitive $\left(F_{(2,5)}=12.68, \mathrm{p}<0.01\right)$ but a bit more tiring $\left(F_{(2,5)}=3.95\right.$, $\mathrm{p}<0.04)$ although workload of maintaining heading or altitude was not significantly different among the controllers (Table 3 ). Also, there was a trend for subjects preferring the positional glove a bit more than the sidestick and rate glove although the difference was not significant $\left(F_{(2,5)}=3.88, \mathrm{p}<0.09\right)$.

Table 3. Means of Subjective Ratings for Ability to Control, Intuitiveness, and Invigorating / Tiring

\begin{tabular}{|c|c|c|c|c|}
\hline \multirow[b]{2}{*}{$\begin{array}{c}\text { Controller } \\
\text { Type }\end{array}$} & \multicolumn{4}{|c|}{ Mean for } \\
\hline & $\begin{array}{l}\text { Control } \\
\text { Heading }\end{array}$ & $\begin{array}{l}\text { Control } \\
\text { Altitude }\end{array}$ & Intuitive & $\begin{array}{l}\text { Invigor } \\
\text {-ating / } \\
\text { Tiring }\end{array}$ \\
\hline Sidestick & 50 & 50 & 50 & 38 \\
\hline Glove-Rate & 30 & 37 & 34 & 50 \\
\hline $\begin{array}{l}\text { Glove- } \\
\text { Positional }\end{array}$ & 18 & 22 & 28 & 50 \\
\hline
\end{tabular}

$0=$ hard to control, not intuitive, tiring

$100=$ easy to control, intuitive, invigorating 


\section{DISCUSSION}

This study looked at whether speeding a simulation (or the "world") would lend itself to objectively indexing a subject's workload and discriminating between control concepts, and whether an operator could control the pitch and bank angle of a simulated business jet using hand motions. It was expected that using natural hand movements would make controlling the aircraft easier and more intuitive. This was accomplished by having pilots and non-pilots make altitude and heading changes using three different controller types/methods each at three different simulation speeds.

Contrary to expectations, results indicate that changing simulation speed does not improve the discriminability of reported workload differences. Subjects reported a higher $\mathrm{CH}$ controllability rating depending on simulation speed and controller type but the greatest differentiation of workload occurred at the real time point. At higher simulation speeds the sidestick and positional glove controllers had equivalent $\mathrm{CH}$ controllability ratings. However, the time it took subjects to reply to questions during each run increased with simulation speed. A simple verbal and mental task (addition problem) had less effect on the time it took a subject to answer than a verbal and searching task (orientation question). The larger increase in time to answer for the verbal searching task was expected because this task shared visual resources with the main task of flight path following.

The bank and pitch angle RMS errors were affected by simulation speed; the error grew as the simulation speed increased. Simulation speed by controller type interaction was not significant for bank and pitch angle RMS errors. This was most likely related to the finding that the flight path following task was given a relatively low $\mathrm{CH}$ controllability rating. However, the slope of both RMS errors across simulation speeds was different among the controller types, with the glove-positional type degrading the slowest as simulation speed increased. This suggests that the glove-positional controller type (where the hand angle is directly proportional to the commanded aircraft angle) may be the most robust under increasing workload.

Also supporting the benefit of the glove-positional controller were the results from the other independent variables: pilot status and controller type. Results indicated that pilots could control the bank and pitch angle of an aircraft about equally as well with the glove as with the sidestick. Non-pilots approached the pilots' ability to control the bank and pitch angle of an aircraft using the positional glove. Subjects reported that the positional glove was also easier to control and more intuitive. Subjects did find the glove controller to be more tiring over that of the sidestick. This is not surprising in that subjects had to hold their hands up during the data runs rather than resting them on a chair arm as they did with the sidestick controller.

Using your hand to control the attitude of an aircraft may exemplify the concept of an embodied user interface since the control of the object is integrated into the object (Bartlett, 2000). The majority of the operators find the embodied user interface easier to operate (Bartlett, 2000). The results do show that non-pilots can approach the performance of pilots very quickly on controlling the bank and pitch angle of an aircraft using their hands to mimic the movement of the airplane. Besides aircraft, this concept could be applied in other areas, including UAVs and remote manipulators used in space, telesurgery (Bonsor, 2007), the nuclear industry, and laboratories.

Changing simulation speed is an experimental method designed to extend the usefulness of primary task performance measurement in assessing workload. The universal nature of the method is such that human-in-the-loop simulations of many types can employ it. The results of the present study indicate that the method has the potential to differentiate interface concepts based upon performance if the task being studied is sufficiently challenging.

\section{REFERENCES}

Bartlett, J. F. (2000). Rock 'n' Scroll Is Here to Stay. IEEE Computer Graphics and Applications, 20(3), 40-50.

Bluck, J. (2001, February 1, 2001). NASA Scientists Use Hands-Off Approach to Land Passenger Jet. 2003, from http://amesnews.arc.nasa. gov/releases/2001/01 images/bioelectric/bioelectric.html

Bonsor, K. (2007). How Robotic Surgery Will Work. 2007, from http://electronics.howstuffworks.com/robotic-surgery.htm

Byers, J. C., Bittner, A. C., \& Hill, S. G. (1989). Traditional and Raw Task Load Index (TLX) Correlations: Are Paired Comparisons Necessary? Advances in Industrial Ergonomics and Safety, 481-485.

Cooper, G. E., \& Harper, R. P. (1969). The Use of Pilot Rating in the Evaluation of Aircraft Handling Qualities: Technical Report 567, AGARD.

Federal Aviation Administration. (2006, December 28). FAA Code of Federal Regulations, Title 14, Vol. 1, Chapt. 1, Part 61, Subpart D - Third-Class Airman Medical Certificate. from http://ecfr.gpoaccess.gov/cgi/t/ text $/$ text-idx? $=$ ecfr\&sid $=46752707 \mathrm{cc} 62 \mathrm{c} 5 \mathrm{~d} 5 \mathrm{ae} 028 \mathrm{adbe} 7884 \mathrm{c} 01 \& \mathrm{rgn}=$ div5\&view=text $\&$ node $=14: 2.0 .1 .1 .5 \&$ idno $=14 \# 14: 2.0 .1 .1 .5 .4$

Fifth Dimension Technologies -- 5DT. (2000). 5DT Data Glove 5 User's Manual Version 2.00.

Fitzmaurice, G. W., Ishii, H., \& Buston, W. (1995). Bricks: Laying the Foundation for Graspable User Interfaces. Paper presented at the Conference on Human Factors in Computing Systems.

Harper, R. P., \& Cooper, G. E. (1986). Handling Qualities and Pilot Evaluation (Wright Brothers Lecture in Aeronautics). Journal of Guidance, Control, and Dynamics, 9(6), 515-529.

Hart, S. G., \& Staveland, L. E. (1988). Development of a NASA-TLX (Task Load Index): Results of Empirical and Theoretical Research. In P. S. Hancock \& N. Meshkati (Eds.), Human Mental Workload (pp. 139-183). Amsterdam: Elsevier Science Publishers B. V.

Hogan, N. (1976). A Review of Methods of Processing EMG for Use as a Proportional Control Signal. Biomedical Engineering, 81-86.

Milgram, P., Zhai, S., \& Drascic, D. (1993, July 1993). Applications of Augmented Reality for Human-Robot Communication. Paper presented at the 1993 IEEE/RSJ International Conference on Intelligent Robots and Systems.

Pope, A. T., \& Bowles, R. L. (1982). A Program for Assessing Pilot Mental State in Flight Simulators. American Institute of Aeronautics and Astronautics, 82-0257.

Saitek Ltd. (2003). Saitek evo User Manual: V1.0 SD-evo 260603: Saitek Ltd. Schutte, P. C. (1997). WINGS: A New Paradigm in Human-Centered Design. Hampton, VA: NASA Langley Research Center.

\section{ACKNOWLEDGEMENTS}

The authors would like to thank Messrs. Lucas Hempley and John Barry of Lockheed Martin for programming the simulation and helping with data collection and preliminary analysis. 